\title{
A GAS ION SOURCE FOR RADIOCARBON MEASUREMENTS AT 200 kV
}

\author{
M Ruff ${ }^{1,2} \bullet$ L Wacker $^{3,4} \bullet$ H W Gäggeler ${ }^{1,2} \bullet$ M Suter $^{3} \bullet$ H-A Synal $^{5} \bullet$ S Szidat $^{1,2}$
}

\begin{abstract}
The novel tabletop miniaturized radiocarbon dating system (MICADAS) at ETH Zurich features a hybrid Cs sputter negative ion source for the measurement of solid graphite and gaseous $\mathrm{CO}_{2}$ samples. The source produces stable currents of up to $6 \mu \mathrm{A} \mathrm{C}^{-}$out of gaseous samples with an efficiency of 3-6\%. A gas feeding system has been set up that enables constant dosing of $\mathrm{CO}_{2}$ into the $\mathrm{Cs}$ sputter ion source and ensures stable measuring conditions. The system is based on a syringe in which $\mathrm{CO}_{2}$ gas is mixed with $\mathrm{He}$ and then pressed continuously into the ion source at a constant flow rate. Minimized volumes allow feeding samples of 3-30 $\mu \mathrm{g}$ carbon quantitatively into the ion source. In order to test the performance of the system, several standards and blanks have successfully been measured. The ratios ${ }^{14}{ }^{14} \mathrm{C} /{ }^{12} \mathrm{C}$ could be repeated within statistical errors to better than $1.0 \%$ and the ${ }^{13} \mathrm{C} /{ }^{12} \mathrm{C}$ ratios to better than $0.2 \%$. The blank was $<1 \mathrm{pMC}$.
\end{abstract}

\section{INTRODUCTION}

More than 20 years ago, Middleton (1984) tested a Cs sputtering ion source to form $\mathrm{C}^{-}$ions directly from $\mathrm{CO}_{2}$ gas on titanium targets. The sample preparation is simplified working with a gas ion source, avoiding the graphitization step needed for solid targets. The graphitization is time consuming and samples $<50 \mu \mathrm{g}$ require great efforts for preparation and measurement. Losses during the graphitization and increased blank values are described (Weissenbök et al. 2000; Steier et al. 2006; Jenk et al. 2007), so that for small samples, direct $\mathrm{CO}_{2}$ measurements seem to be an alternative solution. At the beginning, indeed, the results were very encouraging (Bronk and Hedges 1987, 1990; Middleton et al. 1989). Over the last few years, progress slowed down and only in Oxford have direct measurements of $\mathrm{CO}_{2}$ gas been performed on a routine basis (Bronk Ramsey et al. 2004).

A major problem of gas ion sources is low negative ion currents (Uhl et al. 2004), typically about 10 times lower as compared to solid graphite targets. For high-precision radiocarbon dating, this is a major drawback as the measuring time is up to 10 times longer. Additionally, the construction of a gas handling system to feed the ion source continuously with $\mathrm{CO}_{2}$ gas is not a trivial task. A very low $\mathrm{CO}_{2}$ flow rate of $<4 \mu \mathrm{L} / \mathrm{min}$ (STP) $(<2 \mu \mathrm{g} / \mathrm{min}$ carbon) seems to be best for high sputtering efficiencies of about 10\% (Bronk and Hedges 1987, 1990; Middleton et al. 1989). The size of the gas handling system has to be adapted to sample sizes to avoid contamination. Furthermore, it is difficult to constantly dose small amounts of $\mathrm{CO}_{2}$ into the gas ion source to get stable measuring conditions.

There is a great potential for direct gas measurements, e.g. for biomedical applications, which often make it necessary to perform many ${ }^{14} \mathrm{C}$ analyses of small chromatographic fractions, prone to fail in routine graphitization procedures (Hughey et al. 2000). Furthermore, the apportionment of fossil and non-fossil carbon of airborne aerosols using ${ }^{14} \mathrm{C}$ is becoming increasingly important in atmospheric sciences (Jenk et al. 2006; Steier et al. 2006; Szidat et al. 2006). For this application, typically $<50 \mu \mathrm{g}$ carbon is available per sample and graphitization yields are frequently reduced by interfering reaction gases. In this work, we present a gas handling system for the gas ion source at ETH Zurich that is designed for the measurement of small samples $(<30 \mu \mathrm{g}$ carbon) with moderate precision requirements, aiming at an automated device for high sample throughput.

\footnotetext{
'Department of Chemistry and Biochemistry, University of Bern, Switzerland.

${ }^{2}$ Paul Scherrer Institute, Villigen, Switzerland.

${ }^{3}$ Institute for Particle Physics, ETH Zurich, Switzerland.

${ }^{4}$ Corresponding author. Email: wacker@phys.ethz.ch.

${ }^{5}$ Paul Scherrer Institute, c/o ETH Zurich, Switzerland.
} 


\section{INSTRUMENTAL SETUP}

\section{MICADAS}

An ion source for analyzing $\mathrm{CO}_{2}$ in addition to solid graphite targets has been built for the miniaturized carbon dating system (MICADAS) at ETH Zurich. Principally, the MICADAS system is capable of performing high-precision ${ }^{14} \mathrm{C}$ measurements for dating (Synal et al. 2007). With its compact and simple design as well as easy operation, the system meets the requirements for fast, reliable measurements of small samples in the field of environmental and biomedical applications. For many of these applications, the gas option of the ion source seems to be the better choice.

\section{Gas Ion Source}

In combination with the new accelerator mass spectrometry (AMS) system, it was decided to build a new ion source. The goal was to set up a tabletop-sized system without open high-voltage potentials. First of all, an ion source was built with a vacuum box at ground potential. Thus, all handling operations at the source, e.g. magazine exchange, can be done without interrupting source operation. A turbomolecular pump with $500 \mathrm{~L} / \mathrm{s}$ pumping speed is attached to the ion source box to ensure good vacuum conditions. Thus, negative ion currents of 70-80 $\mu \mathrm{A}$ can be achieved from graphite targets. A more detailed description of the source and its sample changing mechanism is given by Synal et al. (2007).

Gaseous $\mathrm{CO}_{2}$ samples can be analyzed directly with this source in addition to graphite targets without structural changes at the source. A mixture of $\mathrm{He}$ and $\mathrm{CO}_{2}$ is fed into the sputter region. A permanently fixed glass capillary of $2 \mathrm{~m}$ length with an inner diameter of $60 \mu \mathrm{m}$ is used to maintain the pressure gradient between the source vacuum and gas feeding system at 1-2 bar. In addition, this capillary serves as an insulator of the cathode potential of about $-40 \mathrm{kV}$ from the gas feeding system at ground potential. In the sputter region, the $\mathrm{He}-\mathrm{CO}_{2}$ gas mixture is led onto a Ti surface, where $\mathrm{Cs}^{+}$ ions hit the surface and produce $\mathrm{C}^{-}$ions.

\section{Gas Target}

Our target consists of a titanium insert in an aluminium cap (Figure 1). The $\mathrm{He}-\mathrm{CO}_{2}$ gas mixture enters the cap through a hole at the side and streams onto the titanium, where it is sputtered by $\mathrm{Cs}^{+}$ through a 1-mm hole in the front of the aluminium cap. For most measurements, we were using a simple design of titanium inserts with a slit in the surface leading the $\mathrm{CO}_{2}$ to the sputter region (slit target, Figure 1a). We have also tested a series of differently shaped titanium inserts (Figure $1 \mathrm{~b}, \mathrm{c}$ ) to investigate their impact on the sputter yield of negative ions. The tested targets differ in the way the gas enters the sputter region and in the shape of the sputter surface. For these tests, a gas mixture of $2 \% \mathrm{CO}_{2}$ in helium was used with a constant flow of $35 \mu \mathrm{L} / \mathrm{min}$ (STP) $(0.4 \mu \mathrm{g} \mathrm{C} / \mathrm{min})$.
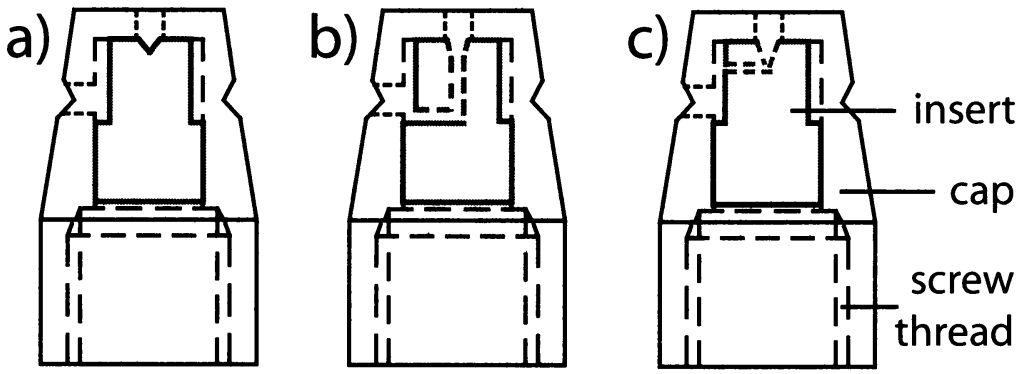

Figure 1 The targets consist of an aluminium cap and a titanium insert, where the gas enters the sputter region a) via a simple slit in the titanium surface, b) longitudinally through a small bore hole, and c) laterally through a small bore hole into a cone. 


\section{Gas Handling System}

A gas handling system to feed the gas ion source with $<30 \mu \mathrm{g}$ carbon as dioxide was built (Figure 2). The heart of our system is a commercially available 1-mL gas-tight syringe (HAMILTON, Reno, USA) with a borosilicate body, a stainless steel needle, and a PTFE-sealed plunger. This syringe serves as an adjustable storage vessel for the gas mixture of $\mathrm{CO}_{2}$ from the sample and helium as a carrier gas. Tightly aligned with a pressure sensor, it is connected to a multi-position valve leading to the ion source or alternatively to an ampoule cracker. In order to minimize dead volumes, a compact system was built with low-volume fittings and valves (VICI Company, Houston, USA) and miniaturized pressure sensors (ENTRAN Devices Inc., Fairfield, USA). The ampoule cracker has a volume of $1.6 \mathrm{~cm}^{3}$ and the syringe one of $1 \mathrm{~cm}^{3}$. The volume of all connecting stainless steel capillaries (ID $0.5 \mathrm{~mm}$ ) is $<0.06 \mathrm{~cm}^{3}$. This was achieved by short distances rather than a minimized inner diameter to maintain a good pumping efficiency in the system.

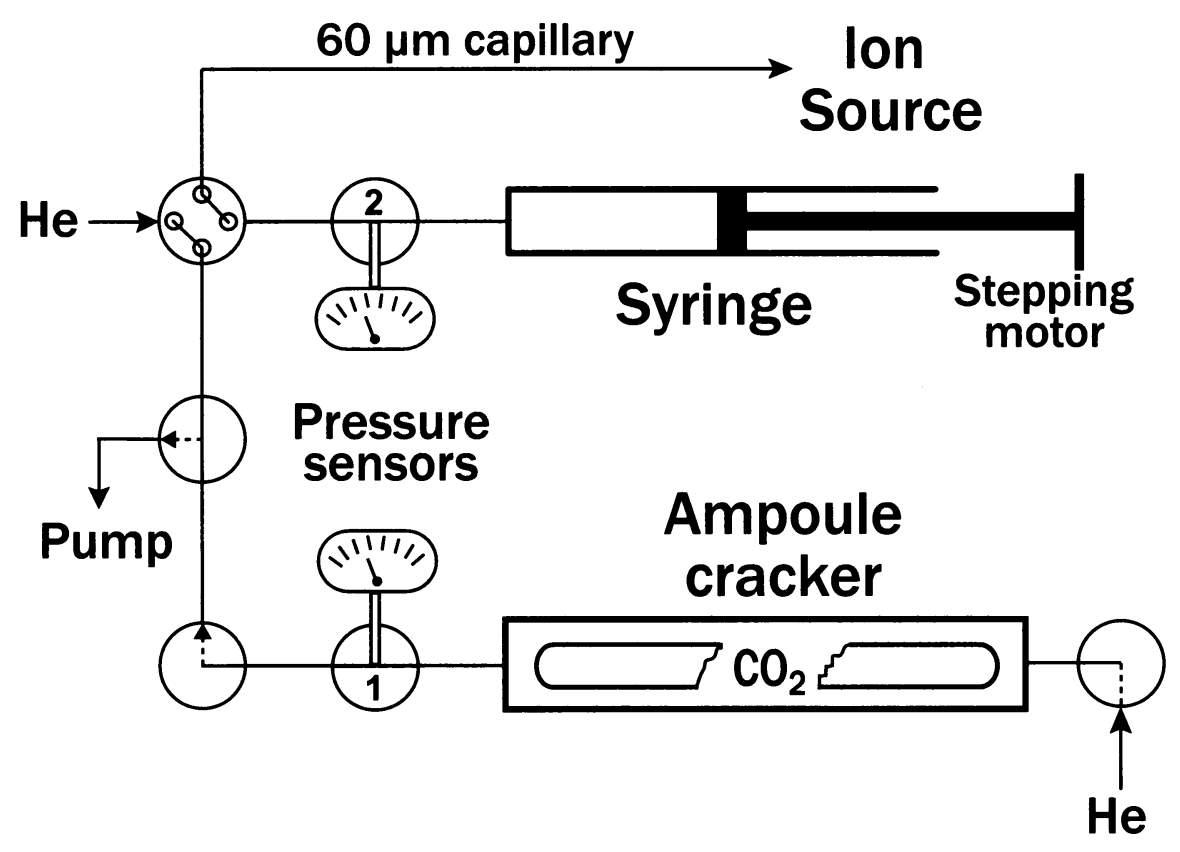

Figure 2 A schematic picture of our gas feeding system

$\mathrm{CO}_{2}$ supplied in a glass ampoule is released in the evacuated cracker and its amount is measured with pressure sensor 1 . The valve between the syringe and the cracker is then opened and already half of the pure $\mathrm{CO}_{2}$ diffuses into the syringe, as the volume of the syringe is similar to the volume of the cracker (volume of the glass ampoule subtracted). In a next step, the syringe is adjusted to a volume corresponding to the amount of $\mathrm{CO}_{2}$. The remaining $\mathrm{CO}_{2}$ in the cracker is flushed with helium to the syringe in 3 steps. This increases the pressure of the gas mixture in the syringe to 1200 mbar (sensor 2). For the whole flushing process, an estimated recovery of $70-90 \% \mathrm{CO}_{2}$ is achieved. The ratio of $\mathrm{CO}_{2}$ and helium in the syringe is now fixed. This mixture is then pressed continuously into the ion source over 5 to $30 \mathrm{~min}$, depending on the amount of $\mathrm{CO}_{2}$. The flow rate of the gas mixture into the ion source is well defined by the pre-pressure on the 2-m fused silica capillary of $60 \mu \mathrm{m}$ diameter. The variation of the pre-pressure caused by the movement of the linear motion drive (stepping motor by SMC Corporation, Tokyo, Japan) is $<1 \%$. 
A second option was built to transfer the $\mathrm{CO}_{2}$ from the cracker to the syringe by freezing out the $\mathrm{CO}_{2}$. A Cu block was constructed for cooling down the middle part of the syringe to $100 \mathrm{~K}$ with liquid nitrogen. To avoid damage to the syringe and leakage at the Teflon ${ }^{\circledR}$ sealing of the plunger, both ends of the syringe are kept at room temperature. The cooling block is additionally equipped with a heating cartridge to accelerate the defrosting process after the $\mathrm{CO}_{2}$ is transferred.

\section{RESULTS AND DISCUSSION}

\section{Performance of the lon Source}

Standard parameters of the gas ion sources are shown in Table 1. For each measurement, a new titanium target is used and pre-sputtered for at least $3 \mathrm{~min}$ to remove carbon contaminants on the surface. This pre-sputtering process reduces the background $\mathrm{C}^{-}$current from up to $1 \mu \mathrm{A}$ to less than $30 \mathrm{nA}$ (Figure 3). At the beginning of a measurement, with a constant $\mathrm{CO}_{2}$ flow into the ion source, the currents are increasing quickly to $\sim 80 \%$ in the first 2 min and then very slowly for about 15 min to $100 \%$ of the maximum current, where it stabilizes. Our gas ion source works efficiently and reliably in the range of $0.5-2 \mu \mathrm{L} / \mathrm{min}$ (STP) of $\mathrm{CO}_{2}(0.25-1 \mu \mathrm{g} \mathrm{C} / \mathrm{min})$. A higher $\mathrm{CO}_{2}$ gas flow results in slightly increased negative ion currents, but lower efficiencies. Furthermore, large carbon deposits can be observed on the target surface if the amount of $\mathrm{CO}_{2}$ is not balanced with the current of the sputtering $\mathrm{Cs}^{+}$ions. Since this graphitization process fractionates the carbon isotopes, large shifts in the isotopic ratios of up to several percent over time would be observed, making repeatable measurements quite difficult.

Table 1 Typical operating conditions and performance of the gas ion source with gas handling system at ETH.

\begin{tabular}{|c|c|}
\hline Parameter & Value \\
\hline $\mathrm{CO}_{2}$ gas flow ${ }^{\mathrm{a}}$ & $0.5-2 \mu \mathrm{L} / \mathrm{min}$ \\
\hline He gas flow ${ }^{a}$ & $35 \mu \mathrm{L} / \mathrm{min}$ \\
\hline Average $\mathrm{C}^{-}$currents & $3-6 \mu \mathrm{A}$ \\
\hline Sputter efficiency $\left(\mathrm{C}^{-}\right)$ & $3-6 \%$ \\
\hline Background currents & $<30 \mathrm{nA}$ \\
\hline Pressure reduction capillary & $2 \mathrm{~m} \times 60 \mu \mathrm{m}$ ID \\
\hline $\mathrm{He}+\mathrm{CO}_{2}$ pre-pressure & 1200 mbar \\
\hline Syringe volume & $1 \mathrm{~cm}^{3}$ \\
\hline Sample size (carbon) & $<30 \mu \mathrm{g}$ \\
\hline Gas handling efficiency & $70-90 \%$ \\
\hline Measuring time & $5-30 \mathrm{~min}$ \\
\hline
\end{tabular}

${ }^{\mathrm{a}}$ Gas volumes normalized to standard conditions.

The currents achieved with our gas ion source under stable conditions are 3-6 $\mu \mathrm{A}$, with maximum observed currents of more than $10 \mu \mathrm{A}$. This is lower than reported by Bronk and Hedges (1987) and Middleton et al. (1989). A reduction of ion currents by a factor of 10 for gas compared to graphite samples, as observed by Middleton et al. (1989), is confirmed by our measurements. At these rather low currents, however, the steady-state efficiency of the source is still 3-6\%. Nevertheless, improvements of ion currents in combination with high negative ion efficiencies are subjects for future investigations. 


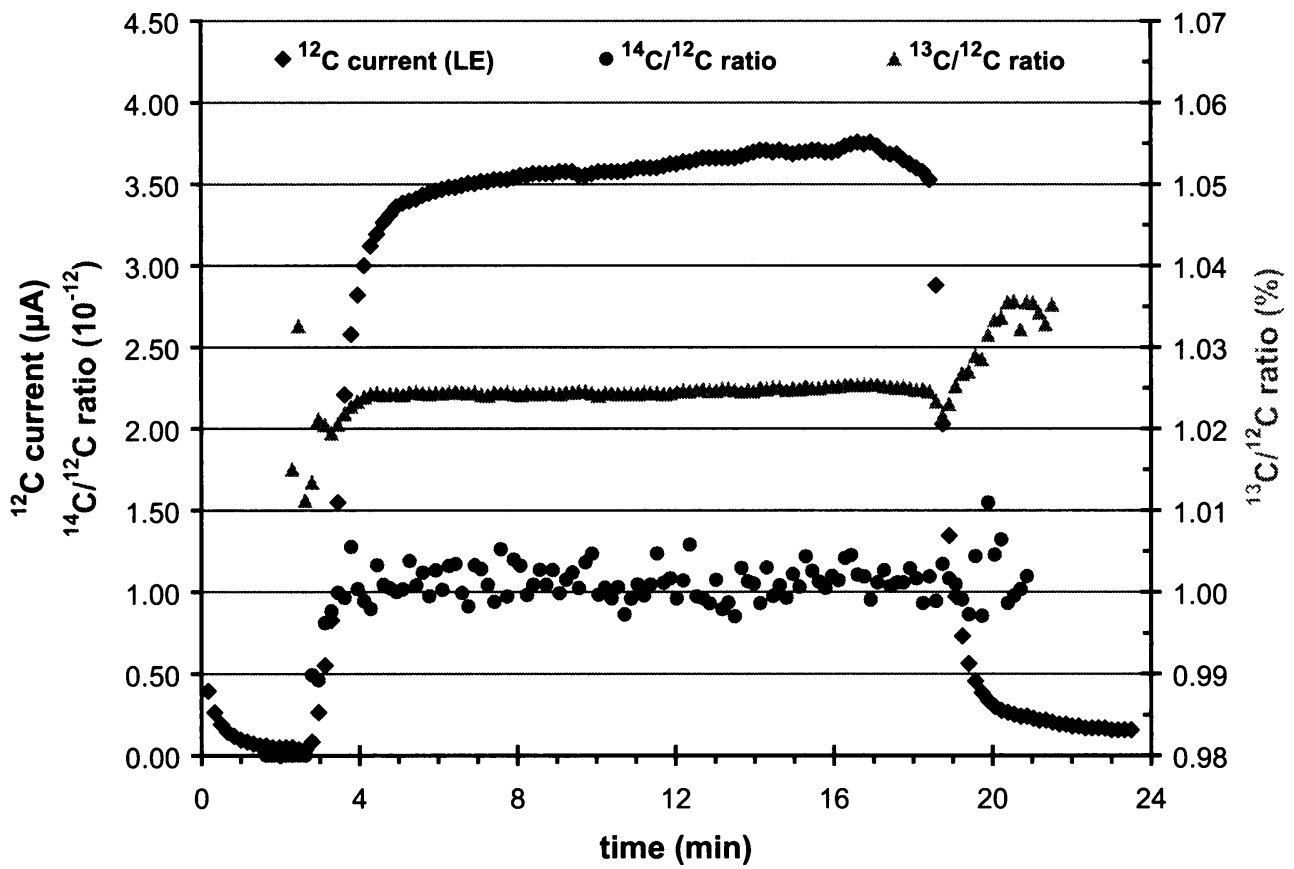

Figure 3 The course of the ${ }^{12} \mathrm{C}$ current at the low-energy (LE) side as well as the ratios of ${ }^{13} \mathrm{C} /{ }^{12} \mathrm{C}$ and ${ }^{14} \mathrm{C} /{ }^{12} \mathrm{C}$ for the measurement of an oxalic acid standard of $15.4 \mu \mathrm{g}$ carbon with a time resolution of $10 \mathrm{~s}$.

In principle, it is desirable to supply the ion source with pure $\mathrm{CO}_{2}$ to maintain a good vacuum, but using a mixture with He simplifies the gas handling (Bronk Ramsey et al. 2004). An He flow rate of 20-50 $\mu \mathrm{L} / \mathrm{min}$ (STP) can be accepted without significantly reducing the efficiency of the sputtering process. Memory effects are reduced with $\mathrm{He}$ added as less $\mathrm{CO}_{2}$ is adsorbed to the walls of the gas handling system. In addition, the tiny amount of $\mathrm{CO}_{2}$ gas needed for a measurement is easier to handle when diluted 10-100 times by volume.

\section{Gas Handling System}

During the 3 min used for the pre-sputtering process of the target, a new sample is transferred from the ampoule cracker to the syringe as described above. The $\mathrm{CO}_{2}-\mathrm{He}$ mixture is pressed very constantly and reproducibly into the ion source with the syringe driven by a linear motion drive running at constant speed of about $0.035 \mathrm{~mm} / \mathrm{s}$. The speed is adjusted once to maintain a certain pre-pressure in front of the capillary, which defines the flow to the ion source with a fluctuation of \pm 10 mbar over the whole measurements. Uhl et al. (2005) previously used a syringe to constantly dose $\mathrm{CO}_{2}$ into the ion source. These authors, however, operated the syringe as a storage vessel for $\mathrm{CO}_{2}$ only and added helium continuously in front of the capillary.

We expected to obtain higher transfer efficiencies when the $\mathrm{CO}_{2}$ is frozen over to the syringe by cooling the syringe with liquid nitrogen, but the currents for some first test samples were rather low. In addition, the freezing-warming process takes about $10 \mathrm{~min}$, significantly more time than a simple flushing. Further tests are required to investigate whether this relatively extensive transfer process can be further improved. 


\section{Measurements}

The machine is now ready for measuring samples manually using a semi-automated control software based on LabVIEW (National Instruments Corporation, Austin, Texas, USA). The course of a typical measurement is shown in Figure 3. During the pre-sputtering process, pure helium is fed into the source. The $\mathrm{CO}_{2}-\mathrm{He}$ mixture coming from the syringe reaches the source $20 \mathrm{~s}$ after the valve to the ion source is switched. Within the next $2 \mathrm{~min}$, the currents rapidly rise and thereafter become quite stable, increasing only very slowly towards the end of the measurement.

The $\mathrm{C}^{-}$currents decrease quickly after the gas flow from the syringe terminates, because the prepressure on the reducing capillary breaks down. Five minutes after the gas flow stopped, we typically observed a current of around $0.1 \mu \mathrm{A}$, which is only about 3 times the background current of the fresh targets.

We have measured a first series of 4 blank $\mathrm{CO}_{2}$ samples using gas from a commercial available $\mathrm{CO}_{2}$ gas bottle (purity 4.6) and 8 OXA I standard $\mathrm{CO}_{2}$ samples. The samples, all in the range of 10-20 $\mu \mathrm{g}$ carbon, were supplied in glass ampoules to determine the performance of our system (Table 2). The measurements were done with a flow of $35 \mu \mathrm{L} / \mathrm{min}$ (STP) gas mixture $(1.25 \mu \mathrm{g} \mathrm{C} / \mathrm{min})$ and our simple slit-target geometry. The very constant ratios of ${ }^{13} \mathrm{C} /{ }^{12} \mathrm{C}$ during the measurements are remarkable (Figure 3 and Table 2). The ratios are at least as constant over the course of a measurement as for solid graphite targets in the same ion source (Synal et al. 2004). Repeatability of a set of samples to $<0.2 \%$ is good.

Table 2 Results of the measurements of the oxalic acid I (OXA) standards and blanks. For the ${ }^{14} \mathrm{C} /$ ${ }^{12} \mathrm{C}$ ratio, the internal error of the counting statistics and the external standard deviations $(1 \sigma)$ of the measuring cycles are shown in percent (values in parentheses). For the ${ }^{13} \mathrm{C} /{ }^{12} \mathrm{C}$ ratios, only the external 1- $\sigma$ deviations are presented. Mean of means and corresponding uncertainties are given representing conditions of multi-sample measurements. All results are given without any blank or background subtraction.

\begin{tabular}{|c|c|c|c|c|}
\hline Sample & $\begin{array}{l}\text { Carbon } \\
(\mu \mathrm{g})\end{array}$ & $\begin{array}{l}{ }^{14} \mathrm{C} /{ }^{12} \mathrm{C} \\
\left(10^{-12}\right)\end{array}$ & $\begin{array}{l}{ }^{13} \mathrm{C} /{ }^{12} \mathrm{C} \\
(\%)\end{array}$ & $\begin{array}{l}{ }^{12} \mathrm{C} \\
(\mu \mathrm{A})\end{array}$ \\
\hline OXA 1 & $<15$ & $1.0483(1.06 / 0.94)$ & $1.0201(0.01)$ & 3.1 \\
\hline OXA 2 & 11.7 & $1.0377(1.44 / 1.40)$ & $1.0210(0.01)$ & 3.1 \\
\hline OXA 3 & 21.4 & $1.0725(0.82 / 0.76)$ & $1.0229(0.01)$ & 4.5 \\
\hline OXA 4 & 18.8 & $1.0490(0.93 / 0.88)$ & $1.0204(0.01)$ & 3.2 \\
\hline OXA 5 & 11.2 & $1.0672(1.40 / 1.12)$ & $1.0250(0.01)$ & 3.0 \\
\hline OXA 6 & 14.4 & $1.0525(1.26 / 1.28)$ & $1.0243(0.02)$ & 4.3 \\
\hline OXA 7 & 17.8 & $1.0543(0.99 / 0.98)$ & $1.0228(0.01)$ & 3.9 \\
\hline OXA 8 & 15.8 & $1.0597(1.08 / 0.95)$ & $1.0231(0.01)$ & 3.7 \\
\hline \multicolumn{2}{|c|}{ Mean uncertainty (single measurement) } & $(1.07 / 1.02)$ & $(0.14)$ & \\
\hline \multicolumn{2}{|c|}{ Mean of means } & $1.0562(0.38 / 0.36)$ & $1.0224(0.05)$ & \\
\hline Blank 1 & 15.0 & $0.0092(11.3 / 11.7)$ & $1.0114(0.01)$ & 3.9 \\
\hline Blank 2 & 21.1 & $0.0075(10.5 / 9.3)$ & $1.0103(0.01)$ & 3.3 \\
\hline Blank 3 & 18.6 & $0.0103 \quad(9.7 / 9.4)$ & $1.0083(0.01)$ & 2.8 \\
\hline Blank 4 & $<10$ & $0.0101(17.0 / 14.9)$ & $1.0079(0.01)$ & 3.0 \\
\hline \multirow{2}{*}{\multicolumn{2}{|c|}{$\begin{array}{l}\text { Mean uncertainty (single measurement) } \\
\text { Mean of means }\end{array}$}} & $(11.2 / 14.4)$ & $(0.16)$ & \\
\hline & & $0.0090(5.6 / 7.2)$ & $1.0095(0.08)$ & \\
\hline
\end{tabular}


The oxalic acid standards repeat very well (Table 2). The external 1- $\sigma$ standard deviation between identical samples for the ${ }^{14} \mathrm{C} /{ }^{12} \mathrm{C}$ ratio is $1.02 \%$, which is in excellent agreement with the value expected from the counting statistics (1.07\%). As the mean of means of Table 2 shows, results similar to solid target measurements $(0.4 \%$ precision for 8 -times standard measurements) are likely possible with repeated measurements, though this would be very time consuming. For all the test measurements described here, the instrument was running in a very stable way over 2 days and no retuning of the instrument was required over this time. The measured ${ }^{14} \mathrm{C} /{ }^{12} \mathrm{C}$ ratio of $9 \times 10^{-15}$ for the blanks (value without any background subtraction of the titanium target) corresponds to $<0.9$ pMC, which is $\sim 4$ times less than for typical blank measurements of solid targets containing only $20 \mu \mathrm{g}$ carbon. Additionally, the blank values seem to be independent of the sample size, which means that the current-dependent blank and standard correction normally applied for small graphite targets (Jenk et al. 2007) can be avoided. After the pre-sputtering process, the ${ }^{14} \mathrm{C}$ count rate of a target was $>4$ times lower than during the blank measurements. Thus, the measured blank originates mainly from the gas handling system and the $\mathrm{CO}_{2}$ ampoule itself. So far, no special precautions have been taken to avoid surface contamination in the gas handling system, and consequently, the blank values may be further reduced. In addition, systematic investigations to determine to what extent scattered molecular fractions are a cause of elevated blank levels have yet to be performed. Hence, an improvement of the possible detection limit can be expected.

\section{Cathode Target Test}

The target types shown in Figure 1 provided very different $\mathrm{C}^{-}$currents. The target with a lateral borehole (Figure 1c) produced $4.7 \mu \mathrm{A} \mathrm{C}^{-}$current compared to about $3.3 \mu \mathrm{A}$ for the simple slit target (Figure 1a) and the target with a longitudinal borehole (Figure 1b). Consequently, a factor of about 1.5 better steady-state efficiency was obtained for the lateral borehole. As in this target $\mathrm{CO}_{2}$ is blown onto the Ti metal to ensure good contact of the gas with the surface of the conically shaped sputter region, we assume that this procedure is important. For the slit targets, we have noticed large graphite deposits on the titanium surface outside the sputter region after the measurement, which may have reduced ion yields. In the future, we will change the target geometry from the slit to the conically shaped target with lateral gas inlet.

\section{CONCLUSIONS AND OUTLOOK}

A gas ion source for the new compact AMS system MICADAS was built and the parameters for optimal operation determined. The source performance was satisfactory with a negative ion yield of 3-6\%. The maximum $\mathrm{C}^{-}$currents are typically $<6 \mu \mathrm{A}$, which is lower than for solid targets. The longer measuring time can be accepted with a compact AMS system such as MICADAS, running more cost-efficiently compared to larger AMS systems. The gas inlet system, based on a cracker for glass ampoules and a gas-tight syringe, allows constant dosing of $\mathrm{CO}_{2}$ mixed with helium into the ion source. This procedure has the advantages that helium can already be used to transfer the $\mathrm{CO}_{2}$ from the cracker into the syringe and that the system is less sensitive to dead volumes. The repeatability of measured standard and blank samples was good. The ratios of ${ }^{14} \mathrm{C} /{ }^{12} \mathrm{C}$ were repeated within statistical errors to better than $1.0 \%$ and the ${ }^{13} \mathrm{C} /{ }^{12} \mathrm{C}$ ratios to better than $0.2 \%$. The blank was size-independent $<1 \mathrm{pMC}$, which is $\sim 4$ times less than for typical blank measurements of solid targets containing $20 \mu \mathrm{g}$ carbon.

Next, we plan to extend our inlet system with an elemental analyzer (EA) in addition to the ampoule cracker as a second option. We will pursue the idea of flushing the $\mathrm{CO}_{2}$ from an EA into the syringe inlet system with He to avoid the more complicated handling with liquid nitrogen cooling. The goal 
is a fully automated system for ${ }^{14} \mathrm{C}$ measurements of small and biomedical samples with minimal effort. The final system is planned to run completely automatically from sample combustion to the ${ }^{14} \mathrm{C}$ measurement with an EA attached to the gas handling system.

\section{ACKNOWLEDGMENTS}

We thank Miriam Wehrli (Bern University) for preparation of standards and blanks as well as Jürg Thut, René Gruber, and Isabelle Altorfer (PSI/ETHZ) for their assistance with the installation of the gas ion source and the gas handling system. We are grateful to PSI and ETHZ, who jointly operate the Zurich AMS facilities.

\section{REFERENCES}

Bronk CR, Hedges REM. 1987. A gas ion source for radiocarbon dating. Nuclear Instruments and Methods in Physics Research B 29(1-2):45-9.

Bronk CR, Hedges REM. 1990. A gaseous ion source for routine AMS radiocarbon dating. Nuclear Instruments and Methods in Physics Research B 52(3-4):322-6.

Bronk Ramsey C, Ditchfield P, Humm M. 2004. Using a gas ion source for radiocarbon AMS and GC-AMS. Radiocarbon 46(1):25-32.

Hughey BJ, Skipper PL, Klinkowstein RE, Shefer RE, Wishnok JS, Tannenbaum SR. 2000. Low-energy biomedical GC-AMS system for ${ }^{14} \mathrm{C}$ and ${ }^{3} \mathrm{H}$ detection. Nuclear Instruments and Methods in Physics Research B 172(1-4):40-6.

Jenk TM, Szidat S, Schwikowski M, Gäggeler HW, Brütsch S, Wacker L, Synal H-A, Saurer M. 2006. Radiocarbon analysis in an Alpine ice core: record of anthropogenic and biogenic contributions to carbonaceous aerosols in the past (1650-1940). Atmospheric Chemistry and Physics 6(12):5381-90.

Jenk TM, Szidat S, Schwikowski M, Gäggeler HW, Wacker L, Synal H-A, Saurer M. 2007. Microgram level radiocarbon $\left({ }^{14} \mathrm{C}\right)$ determination on carbonaceous particles in ice. Nuclear Instruments and Methods in Physics Research B 259(1):518-25.

Middleton R. 1984. A review of ion sources for accelerator mass spectrometry. Nuclear Instruments and Methods in Physics Research B 5(2):193-9.

Middleton R, Klein J, Fink D. 1989. A CO 2 negative ion source for ${ }^{14} \mathrm{C}$ dating. Nuclear Instruments and Methods in Physics Research B 43(2):231-9.

Steier P, Drosg R, Fedi M, Kutschera W, Schock M,
Wagenbach D, Wild EM. 2006. Radiocarbon determination of particulate organic carbon in non-temperated, alpine glacier ice. Radiocarbon 48(1):69-82.

Synal H-A, Döbeli M, Jacob S, Stocker M, Suter M. 2004. Radiocarbon AMS towards its low-energy limits. Nuclear Instruments and Methods in Physics Research B 223-224:339-45.

Synal H-A, Stocker M, Suter M. 2007. MICADAS: a new compact radiocarbon AMS system. Nuclear Instruments and Methods in Physics Research B 259(1): 7-13.

Szidat S, Jenk TM, Synal H-A, Kalberer M, Wacker L, Hajdas I, Kasper-Giebl A, Baltensperger U. 2006. Contributions of fossil fuel, biomass-burning, and biogenic emissions to carbonaceous aerosols in Zurich as traced by ${ }^{14} \mathrm{C}$. Journal of Geophysical Research 111: D07206; doi:10.1029/2005JD006590.

Uhl T, Kretschmer W, Luppold W, Scharf A. 2004. Direct coupling of an elemental analyzer and a hybrid ion source for AMS measurements. Radiocarbon 46(1): 65-75.

Uhl T, Kretschmer W, Luppold W, Scharf A. 2005. AMS measurements from microgram to milligram. Nuclear Instruments and Methods in Physics Research B 240(1-2):474-7.

Weissenbök RH, Currie LA, Gröllert C, Kutschera W, Marolf J, Priller A, Puxbaum H, Rom W, Steier P. 2000. Accelerator mass spectrometry analysis of nonsoluble carbon in aerosol particles from high alpine snow (Mt. Sonnblich, Austria). Radiocarbon 42(2): 285-94. 